It may be noted that baker's yeast contains about $4 \mathrm{mgm}$. of potassium per gm., of which about 15 per cent can be washed out, while the rest is retained. All experiments were made with yeast which, after washing for several hours, was in equilibrium with suspension fluid as regards potassium.

The experiments show that potassium is taken up by the yeast cells simultaneously with the glycogen formation, and that with the breakdown of glycogen it is again liberated. It is a probable assumption that this movement of potassium is connected with the production of phosphoric esters of the sugars as intermediate reactions in the polymerization and breakdown of glycogen. This would agree with our findings on the role of potassium in carbohydrate metabolism in animals ${ }^{2}$.

A detailed report will be published later.

$$
\begin{array}{ll}
\text { Physiological Institute, } & \text { R. PULver. } \\
\text { University of Basle, } & \text { F. VerzÁr. } \\
\text { Switzerland. } & \\
\text { April 10. } &
\end{array}
$$

' Willstätter, R., and Rohdewald, M., Enzymolojia, 8, 1 (1940).

² Verzár, F., and Somogyi, J. C., NATuRE, 144, 1014 (1939); 145, 781 (1940).

\section{Seed Disinfection}

Certaln proprietary seed disinfectants and protectives which contain organo-mercury compounds as their fungicidal basis are now used extensively for disinfecting cereal seed prior to sowing. When correctly used they give an excellent control of many seed-borne diseases, but in some circumstances, injury to the grain may result, and it is the purpose of this note to indicate those conditions which may lead to such injury. These materials are also used for treating such seeds as peas, sugar-beet, etc., but the observations given here are confined to cereals.

In these seed disinfectants, the fungicidal salt is often a member of the series $R$. $\mathrm{Hg} . X$, where $R$ is a hydrocarbon and $X$ an acidic radicle. In some cases mixtures of such salts are used. In this series there is a close relationship between composition and fungicidal power, the toxicity decreasing with the increase of the molecule of $R$. In certain circumstances such salts may produce a characteristic phytocidal effect when they are applied to, and held by, the grain in over-doses. The seed may be killed outright or it may commence to germinate and the coleoptile to appear, but further development is abnormal, characterized by thickening of the tissues of the coleoptile and stunting of the roots. Porter ${ }^{1}$ reports that such seedlings have thickened leaf primordia with irregular crenations and lobes. Cell division is inhibited, the existing cells becoming enlarged and multinucleate, either with small nuclei or with large 'giant nuclei' which are polyploid.

We have observed that the primary roots are usually short and thickened, their development being arrested soon after they emerge. Root hairs are frequently absent, and in these cases the seminal roots are usually discoloured brown.

Typically abnormal seedlings seldom develop further, and neither they nor the killed seeds decay rapidly in the soil. We have noted this characteristic injury both in laboratory tests and in the field and we have investigated those conditions under which it may be induced. The effect of these dust disinfectants upon seed which has been treated and then stored under varying conditions has also been examined.
We have found that provided the grain shows relatively high initial germination, is of sound physical condition and is superficially dry when dusted with these materials, then no immediate injury to the grain is likely to result. If such seed has to be stored, then provided it is kept under dry, cool conditions, with adequate ventilation, it is unlikely that any significant loss of germination capacity will ensue during several months. With such wellconditioned seed it is not possible to give any markedly excessive doses, as the dust cannot be retained by superficially dry seed beyond a certain limit.

A factor of some importance appears to be the relative superficial moisture of the seed. If such seed is dusted, even at the recommended rate, that part of the bulk of seed upon which the dressing falls will retain excessive quantities. The subsequent mixing will result in a distribution throughout the bulk of a proportion of heavily over-dusted seeds. These may be killed or may produce abnormal seedlings, thus resulting in an uneven stand. Intentional or accidental application of dust to damp seed, at rates higher than those recommended, will tend to produce more markedly adverse results.

Injury may also result if dry and well-conditioned grain is treated at normal rates but is afterwards stored under damp conditions with poor ventilation.

The moisture content of the seed (as opposed to superficial moisture) is another factor we have investigated, but we have obtained little or no evidence that treated seed of a moisture content slightly above normal suffers any immediate and serious phytocidal effects. Preliminary observations suggest that seed of high moisture content which has been dusted at normal rates and then stored suffers loss of viability to no greater degree than does undusted seed of similar moisture content.

W. A. R. Dillon Weston.

School of Agriculture, Cambridge.

C. C. Brett.

Official Seed Testing Station, Cambridge.

'Porter, R. H., "Relation of Seed Disinfectants to Seed Analysis". Proceedings of the Association of Official Seed Analysts of North America (1936).

\section{Origin of the Frow Remedy for Acarine Disease of Honey Bees}

Is 1927, Mr. R. W. Frow, of Wickenby, Lincolnshire, introduced the use of the remedy (since known by his name) as a cure for acarine disease. Mr. Frow informs one of us (A. D. B.) that he has no record of the origin of the formula, but believes that he read of it in a newspaper as a means of combating freeliving acari.

We are anxious to trace the origin of the formula, which is :

$\begin{array}{lll}\text { Nitrobenzene } & . & 2 \text { parts (by measure) } \\ \text { Safrol oil : } & \text { 3 part } \\ \begin{array}{l}\text { Petrol (preferably } \\ \text { 'Summer Shell') }\end{array} & \text { · } & 2 \text { parts }\end{array}$

Strood Cottage,

Broadbridge Heath,

Horsham, Sussex.

School of Beekeeping,

Seale Hayne College,

Newton Abbot, Devon.
A. D. Betts.
D. Morland. 